\title{
Integrated Life Cycle Design Approach for Sustainable Product Development
}

\author{
B. Lu, P. Gu, S. Spiewak \\ Department of Mechanical and Manufacturing Engineering \\ The University of Calgary \\ Calgary, Alberta, Canada T2N 1N4 \\ pgu@ucalgary.ca
}

\begin{abstract}
Sustainable product development (SPD) requires that product design achieve minimal or zero environmental impact, while satisfying other design criteria such as functionality, quality, desirable features, and acceptable cost and time to market. Therefore, environmental evaluations must be incorporated into the design stage. This research is aimed at the development of a new approach to lifecycle design and evaluation. This paper proposes a framework to optimize functional, environmental, and economic (FEE) performance towards sustainable design. Based on the three dimensions of FEE, a systematic lifecycle design process model is proposed, which consists of: the three FEE requirements; two design objects (physical structure and lifecycle structure); and, the FEE evaluation streams of LCQ (functional lifecycle quality), LCA (environmental lifecycle assessment) and LCC (economic lifecycle costing). A new concept, called process-based analysis (PBA) is defined, and used as the base for FEE evaluations.
\end{abstract}

\section{Introduction}

Products impact the environment in various aspects within their lifecycles. Once a product design is completed for production, the environmental attributes of the product have largely been determined. Most of the traditional product design requirements focus mainly on product functionality, quality and cost in order to meet customer requirements. From the viewpoint of sustainable development, such traditional design requirements should be extended to include environmental criteria. Sustainable development concerns three dimensions - social, environmental, and economic. Thus, a suitable design method should systematically optimize the entire product lifecycle of functional, environmental, and economic performance.

Most design research and theories have been function-based, including Axiomatic Design, QFD (Quality Function Deployment), Taguchi, and TRIZ.
These methods have been used for design analysis and evaluation [Suh, 2001; Taguchi, 2000; Kim, 2000].

In design for the environment, a wide range of research has been carried out, such as: the integration of product and process design with material selection; the development of models for assessing the integration of consumer demand and product use, disposal or recycling; the improvement of methods, tools and procedures for evaluation of the risks associated with environmental hazards and of the cost or benefit; the substitution of materials with lower environmental impact in processing or in the final product; the advancement of techniques for forecasting the effects of specific governmental regulations over the complete product lifecycle and for new or improved manufacturing processes; and, the development of new bulk materials and coatings with increased life spans that can be manufactured with decreased environmental impact. The most contributions have come from lifecycle engineering techniques.

The lifecycle viewpoint is the cornerstone of sustainable design. Lifecycle assessment (LCA) and lifecycle costing (LCC) are the major techniques for dealing with environmental impact assessment and cost. They have become part of the ISO 14000 standard.

To achieve the objective of sustainable product design, the functional, environmental and economic objectives should be optimized simultaneously. Evaluations in these three dimensions should be carried out early in the design process, as it is considered the most effective time for improving product design and performance.

Targeting sustainable product design, this research has constructed a new design process model based on lifecycle objectives. It consists of three design requirements, two design objects, and three streams of evaluations. The three design requirements include FEE: functional requirements derived from customer needs, environmental requirements that reflect 
society's needs for protecting natural resources and the environment, and the economic requirements that ensure the company's business goals. Accordingly, two design objects are carried out simultaneously - the physical structure and the lifecycle structure. These two objects are represented by two groups of design parameters - physical parameters and lifecycle parameters. In the comprehensive evaluation phase of product design, the three analysis streams are the functional lifecycle quality (LCQ) analysis, the environmental lifecycle assessment (LCA), and the economic lifecycle cost (LCC) assessment, which are conducted with respect to FEE requirements.

In order to conduct design analysis and evaluation, more attention needs to be given to the lifecycle structure. As the physical structure may be evaluated through the entire lifecycle, the lifecycle structure will determine the evaluation boundary. A process-based analysis (PBA) concept is proposed for the analyses of all three streams - LCQ, LCA, and LCC. Functional analysis defined by LCQ is carried out by integrating robust design and axiomatic design into a single design framework.

LCA could be used in the design process to determine the most environment-friendly product design among available design alternatives. It can also provide insight into the main causes of a product's environmental impact. Thus, design priorities and product design guidelines can be established based on the LCA data. In this paper, a simplified LCA methodology is formed and used for LCA stream - the environmental evaluation - that explores LCA application in the early design stage. Detailed assessment techniques are also developed for effective design evaluations.

\section{Design Process}

One of the research objectives was to address functional, environmental, and economic evaluations during the design stage. The idea was to develop a new general design process model and associated evaluation approaches.

From a lifecycle point of view, one way to achieve sustainability is to close lifecycle loops by selecting suitable processes for each lifecycle stage. This means that designers must design not only the product's physical structure but also its lifecycle structure. In general, there are four main stages in a product lifecycle structure: the extraction, the production, the operation and the retirement. Each stage may have one or more processes. For example, the operation stage may consist of use, maintenance, and repair; the retirement stage may include reuse, remanufacturing, recycling and/or deposit in landfills. Inputs and outputs of every process may impact the product in terms of functional performance, environmental effect, and economic result. Figure 1 depicts the product's physical structure.

Figure 2 depicts a typical product lifecycle structure. In the extraction stage, materials and energy are obtained from natural resources. In the production stage, the materials are manufactured into product components, and then assembled into products. In the operation stage, the products are used and their lifespan may be improved by services (maintenance and repair). In the retirement stage, the products may be directed to reuse, recycling or the landfill. The objective of the systematic lifecycle design is to create closed loops for sustainable product lifecycle that can minimize waste, material and energy consumption, and emission generation from the perspective of the whole lifecycle.

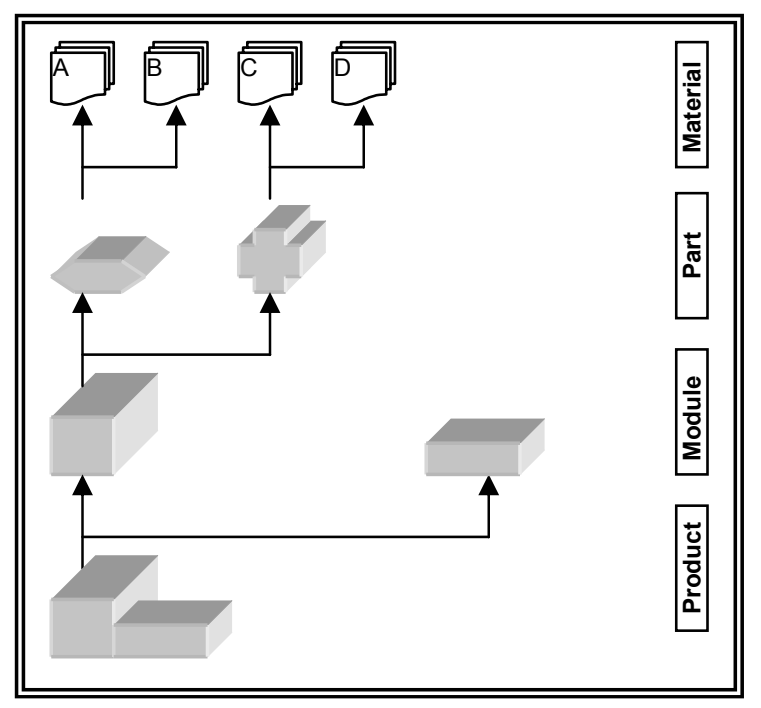

Figure 1. Product Physical Structure

Based on the above discussion, a systematic lifecycle design process model (as indicated in Figure 3 ) is proposed, in order to achieve the goal of designing the product with an optimal lifecycle by satisfying the FEE design requirements, the two design objects and the FEE streams of design evaluations. The three FEE requirements may be defined as follows:

- Functional requirements $\left(\mathbf{R}_{\mathrm{fu}}\right)$ : derived from customer needs and reflect the product's main purpose;

- Environmental requirements $\left(\mathbf{R}_{\text {en }}\right)$ : reflect society's need to protect its natural resources and the environment; and,

- Economic requirements $\left(\mathbf{R}_{\mathbf{e c}}\right)$ : the basic business motivation to produce the product. 


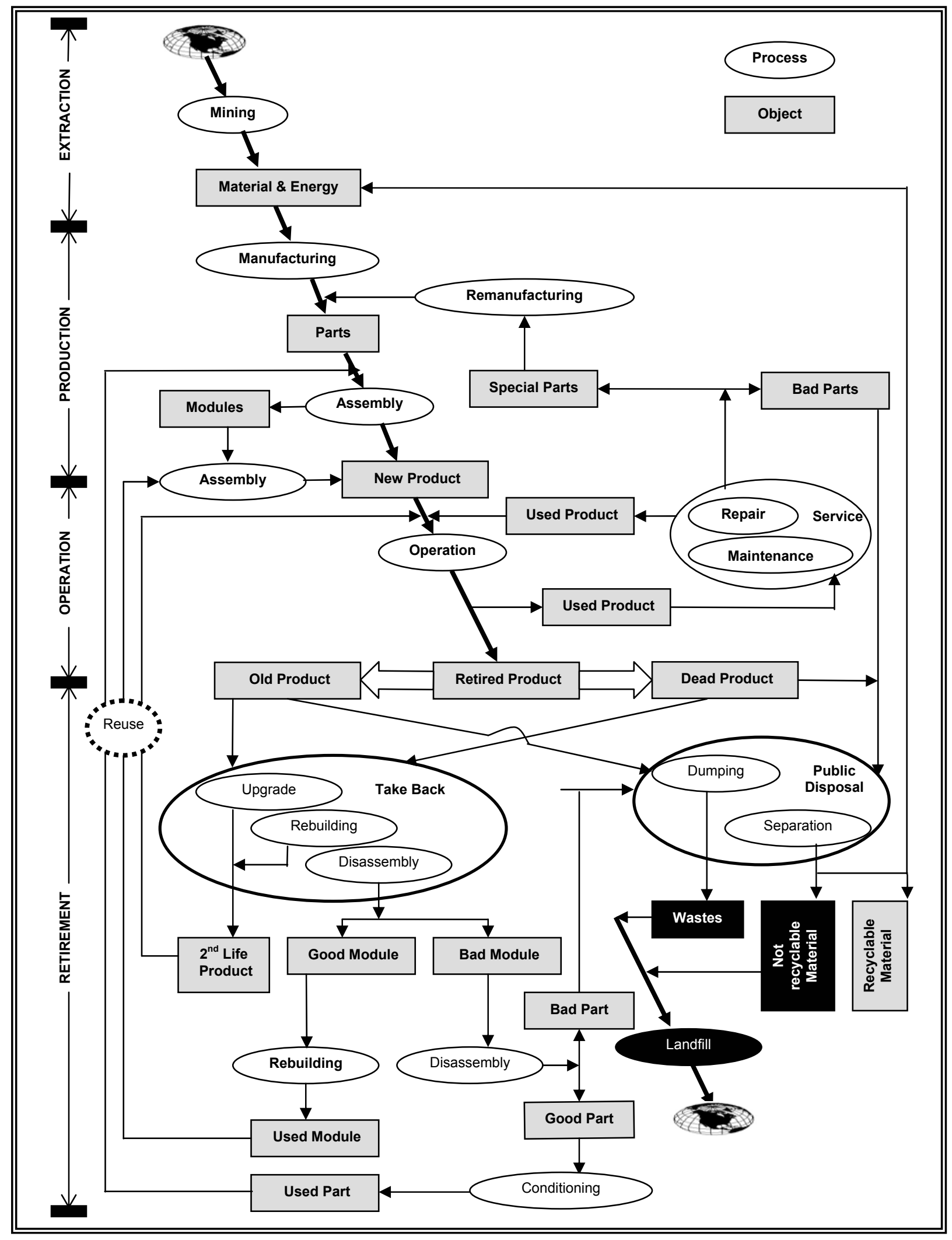

Figure 2. Product Lifecycle Structure 


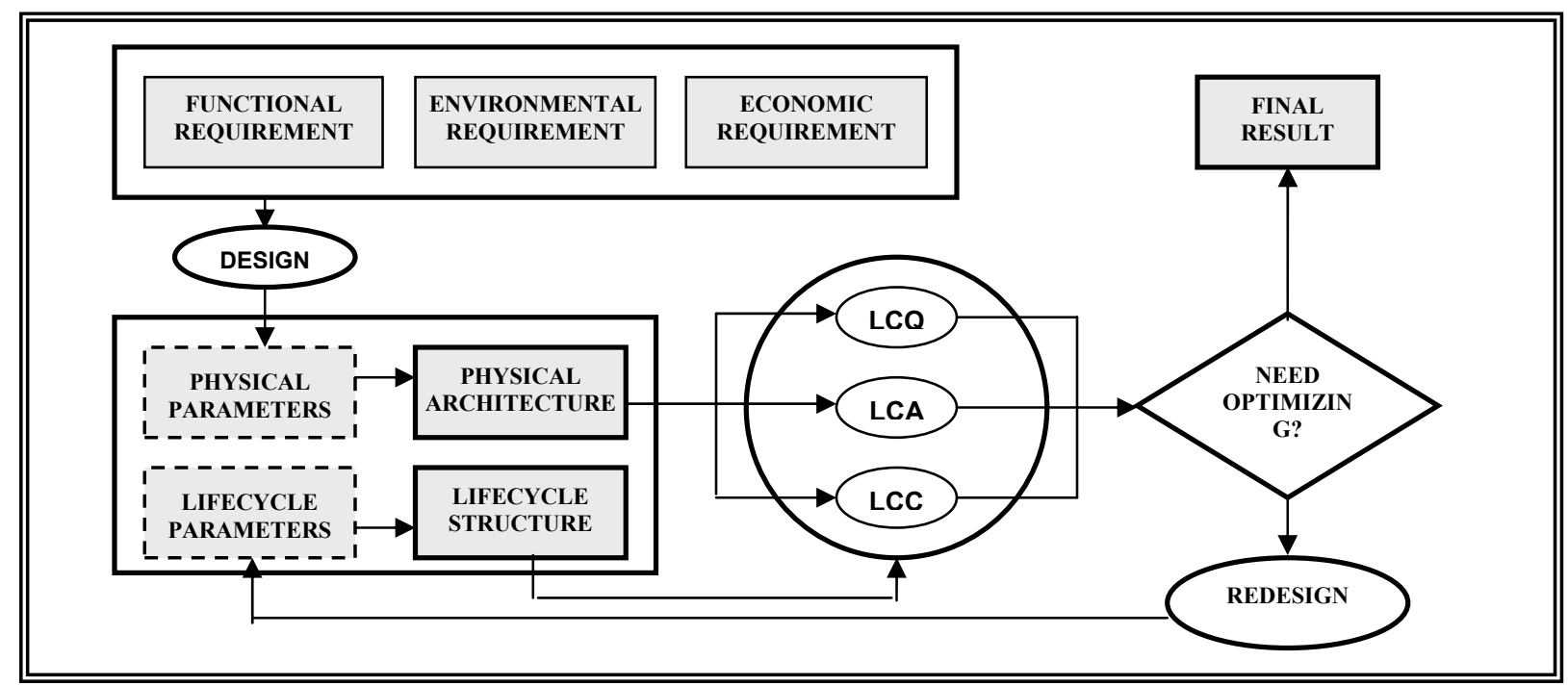

Figure 3. Design Process Model

Design action maps those three requirements to the two groups of design parameters, which determine the two design objects - the physical structure $\left(\mathbf{D R}_{\mathbf{1}}\right)$ and lifecycle structure $\left(\mathbf{D R}_{\mathbf{2}}\right)$. Therefore, they have relationships with each other:

$$
\begin{aligned}
& \mathbf{R}_{\mathbf{f u}}=\mathrm{F}\left(\mathbf{D R}_{\mathbf{1}}, \mathbf{D R}_{\mathbf{2}}\right) ; \\
& \mathbf{R}_{\mathrm{en}}=\Phi\left(\mathbf{D R}_{\mathbf{1}}, \mathbf{D R}_{\mathbf{2}}\right) ; \\
& \mathbf{R}_{\mathbf{e c}}=\Psi\left(\mathbf{D} \mathbf{R}_{\mathbf{1}}, \mathbf{D R}_{\mathbf{2}}\right) ;
\end{aligned}
$$

where $\mathbf{D} \mathbf{R}_{\mathbf{1}}$ and $\mathbf{D} \mathbf{R}_{\mathbf{2}}$ are relative to each other.

F, $\Phi$ and $\Psi$ depict certain relationships. The next step is the design evaluation. The evaluation is equipped with three assessment streams in regard to the functional, environmental, and economic dimensions. These three streams conduct LCQ, LCA, and LCC analyses. While the lifecycle structure forms the evaluation boundary, the physical structure is evaluated along each stream. Depending on the evaluation results, the process goes to redesign or to the next phase of the design process. The lifecycle structure is detailed to the stages and then to each process. All designed processes determine the boundary within which the object should be evaluated. The evaluation results of each process contribute to the assessment of the stage to which it belongs. The lifecycle assessment is formed from the assessments of all four lifecycle stages together. Thus, process-based analysis (PBA) is proposed for application in all three streams of LCQ, LCA and LCC evaluations. This paper, however, mainly focuses on LCQ and LCA.

The lifecycle model diagram (Figure 2) shows that every two objects are connected by one process. Correspondingly, the process is characterized with inputs and outputs along each stream. Figure 4 shows the three assessment streams within PBA. The following sections will provide more detailed discussions on the new LCQ and LCA approaches.

\section{LCQ - Functional Analysis}

Some mechanical system designs are better, or more robust, than the others. A robust design is one that satisfies requirements while minimizing the effects of environmental variability on product performance [Dunsmore et al., 1997]. Environmental variations may come from raw materials, manufacturing processes, and/or operational environments that cause deviations of product performance and functions.

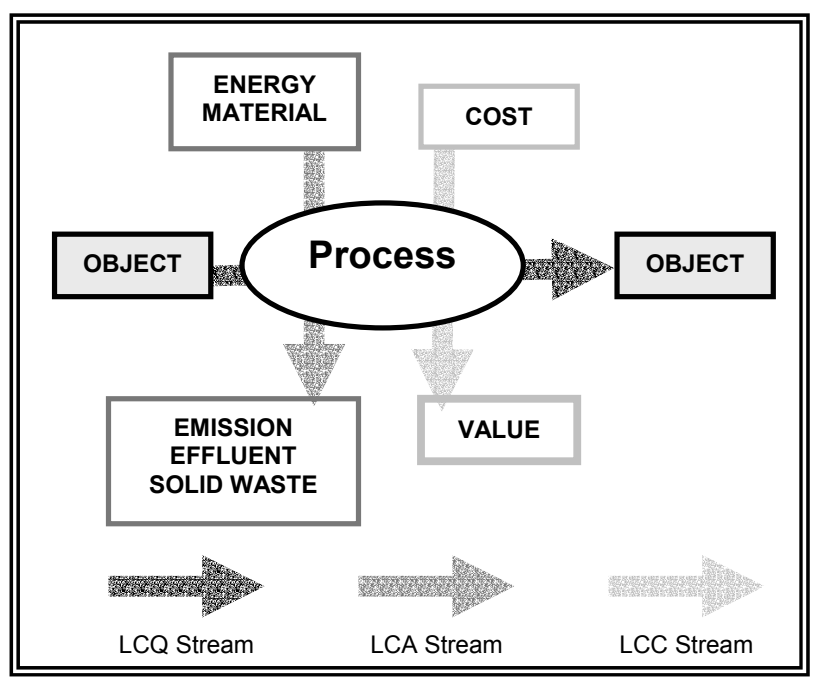

Figure 4. Process-Based Analysis 
It is always desirable to have product performance affected, or only minimally affected, by the operation environment. This robustness is a result of ideal designs that obey the independence axiom. In reality, however, not all designs can be functionally independent and still serve their purpose.

Independence and robustness address product design performance in different ways. In this paper, designs are divided into three categories: feasible, robust, and ideal. It is understandable that, sometimes, it is not possible for designers to achieve the ideal goals. A possible approach is: first, generate a feasible design; then, acquire robustness; and then, achieve independence.

This research proposes a unified framework of design independence and robustness. It introduces the integration of the independent analysis, which is based on Suh's Axiomatic Design, and robust analysis, which is based on a traditional robust technique. It can assist the designer in seeking an ideal design or a robust design, in respect to the specific design conditions. Some designs may be neither ideal nor robust. Designers then need to decide whether to keep the designs or to make changes that will achieve the ideal or robust design.

According to Suh's theory, the design process can be considered a procedure mapping from the functional domain to the physical domain [Suh, 2001]. If Fr denotes the functional requirement and $\mathbf{D p}$, the design parameter, then the performance function can be expressed as:

$$
\begin{aligned}
& \mathbf{F r}=f(\mathbf{D p}) \\
& \text { or } \mathbf{F r}=[\mathbf{D}] \cdot \mathbf{D p} \\
& \text { where }(4-1) \\
& \mathbf{F r}=\left[\mathrm{Fr}_{1,}, \mathrm{Fr}_{2}, \mathrm{Fr}_{3,}, \ldots, \mathrm{Fr}_{\mathrm{n}}\right]^{\mathbf{T}} \\
& \mathbf{D p}=\left[\mathrm{Dp}_{1}, \mathrm{Dp}_{2}, \mathrm{Dp}_{3,}, \ldots, \mathrm{Dp}_{\mathrm{m}}\right]^{\mathbf{T}} \\
&\text { [ } \mathbf{D}] \text { is called the design matrix. Dij }=\partial \mathrm{Fri} / \partial \mathrm{Dpj}
\end{aligned}
$$

When $\mathrm{n}>\mathrm{m}$, it is a coupled design; when $\mathrm{n}<\mathrm{m}$, a redundant design. Only when $\mathrm{n}=\mathrm{m}$, does it has a chance to be an ideal design [Suh, 2001]. When $\mathrm{n}=\mathrm{m}$, it can be a coupled design (which does not obey the independence axiom) or a decoupled design (which may conditionally become independent). In this case, $D_{i j}=0$ (when $i \neq j$ ) means an uncoupled design; $D_{i j}=0$ (only when $\mathrm{i}<\mathrm{j}$ ) means a decoupled design; otherwise, $\mathrm{D}_{\mathrm{ij}}$ means a coupled design. An uncoupled design is preferred.

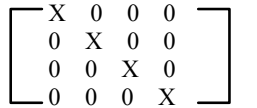

Uncoupled

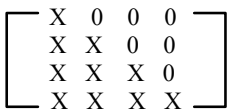

Decoupled

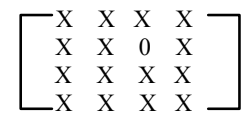

Coupled
Figure 5. Design Matrices
In reality, design parameters in the physical domain may have variations ( $\Delta \mathbf{D p})$ caused by changes in the manufacturing or operation environments. These variations cannot be controlled by designers, but the performance function may not be sensitive to the changes. The design is still robust.

The sensitivity of $\mathbf{F r}$ to changes in the input Dp can be measured by $\mathrm{S}$, which is the ratio of the relative errors in the output and the input:

$\mathrm{S}=\left|\frac{\Delta \mathbf{F r} / \mathbf{F r}}{\Delta \mathbf{D p} / \mathbf{D p}}\right|=\left|\frac{\Delta \mathbf{F r} / \Delta \mathbf{D p}}{\mathbf{F r} / \mathbf{D p}}\right| \approx\left|\frac{\partial \mathbf{F r} / \partial \mathbf{D p}}{\mathbf{F r} / \mathbf{D p}}\right|(4-3)$

Sensitivity, $\mathrm{S}$, is also known as the condition number. Both $\partial \mathbf{F r} / \partial \mathbf{D p}$ and $\mathbf{F r} / \mathbf{D p}$ are performance matrix [D] related terms. Matrix [ D ] is significant as both the functional independence and the sensitivity of a design can be measured by studying [ D ].

The functional deviation caused by environmental variation can be expressed as:

$$
\begin{aligned}
\Delta \mathbf{F r} & =f(\mathbf{D p}+\Delta \mathbf{D} \mathbf{p})-f(\mathbf{D p}) \quad(4-4) \\
\text { or } \quad \Delta \mathbf{F r} & =[\mathbf{D}] \cdot \Delta \mathbf{D} \mathbf{p}
\end{aligned}
$$

where $\Delta \mathbf{D p}$ denotes the design deviation caused by environmental variations.

Mathematically, the covariance and the variancecovariance are often used to measure a certain kind of dependence between variables. Suppose that $\Delta \mathbf{F r}$ and $\Delta \mathbf{D p}$ are real-valued random variables with means $E(\Delta \mathbf{F r})$ and $E(\Delta \mathbf{D} \mathbf{p})$, the means, the variance and the variance-covariance are defined as:

Means:

$$
\begin{aligned}
& E(\Delta \mathbf{F r})=\left[E\left(\Delta \mathrm{Fr}_{1}\right), E\left(\Delta \mathrm{Fr}_{2}\right), \ldots, E\left(\Delta \mathrm{Fr}_{\mathrm{n}}\right)\right]^{\mathrm{T}} \\
& E(\Delta \mathbf{D p})=\left[E\left(\Delta \mathrm{Dp} \mathrm{p}_{1}\right), E\left(\Delta \mathrm{Dp}_{2}\right), \ldots, E\left(\Delta \mathrm{Dp}_{\mathrm{n}}\right)\right]^{\mathrm{T}}
\end{aligned}
$$

Variance:

$$
\begin{aligned}
& \operatorname{Var}(\Delta \mathbf{F r})=E\left\{[\Delta \mathbf{F r}-E(\Delta \mathbf{F r})]^{2}\right\} \\
& \operatorname{Var}(\Delta \mathbf{D p})=E\left\{[\Delta \mathbf{D p}-E(\Delta \mathbf{D} \mathbf{p})]^{2}\right\}
\end{aligned}
$$

Variance-Covariance:

$$
\begin{aligned}
& V C(\Delta \mathbf{F r})=\operatorname{Cov}(\Delta \mathbf{F r}, \Delta \mathbf{F r}) \\
& =E\left\{[\Delta \mathbf{F r}-E(\Delta \mathbf{F r})][\Delta \mathbf{F r}-E(\Delta \mathbf{F r})]^{\mathrm{T}}\right\} \\
& \begin{aligned}
V C(\Delta \mathbf{D} \mathbf{p}) & =\operatorname{Cov}(\Delta \mathbf{D p}, \Delta \mathbf{D p}) \\
& =E\left\{[\Delta \mathbf{D p}-E(\Delta \mathbf{D p})][\Delta \mathbf{D p}-E(\Delta \mathbf{D} \mathbf{p})]^{\mathrm{T}}\right\}
\end{aligned}
\end{aligned}
$$

Thus,

$$
\begin{aligned}
V C(\Delta \mathbf{F r}) & =V C([\mathbf{D}] \cdot \Delta \mathbf{D p}) \\
& =E\left[([\mathbf{D}] \cdot \Delta \mathbf{D p})([\mathbf{D}] \cdot \Delta \mathbf{D p})^{\mathrm{T}}\right] \\
& =E\left([\mathbf{D}] \cdot \Delta \mathbf{D p} \cdot \Delta \mathbf{D} \mathbf{p}^{\mathrm{T}} \cdot[\mathbf{D}]^{\mathrm{T}}\right) \\
& =[\mathbf{D}] \cdot E\left(\Delta \mathbf{D p} \cdot \Delta \mathbf{D} \mathbf{p}^{\mathrm{T}}\right) \cdot[\mathbf{D}]^{\mathrm{T}} \\
& =[\mathbf{D}] \cdot V C(\Delta \mathbf{D} \mathbf{p}) \cdot[\mathbf{D}]^{\mathrm{T}} \quad(4-6)
\end{aligned}
$$

For research purposes, it is assumed that the variations of both design parameters and functions have normal distributions:

$$
E(\Delta \mathbf{F r})=\mathbf{0} \text { and } E(\Delta \mathbf{D p})=\mathbf{0}
$$

The standard variances have uniform values, $\sigma_{\mathrm{F}}$ and $\sigma_{\mathrm{D}}$; their variance-covariance are simply considered to be isotropic: 


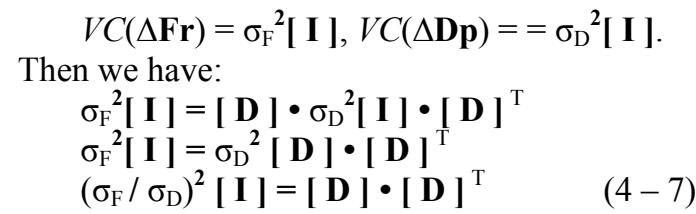

It has been mentioned that sensitivity $\mathrm{S}$ reflects the ratio of the relative errors in the output and the input:

$$
S=\left|\frac{\partial F r / \partial D p}{F r / D p}\right|
$$

Here Dp is the input and $\mathbf{F r}$ is the output.

In Equation $\left(\sigma_{\mathrm{F}} / \sigma_{\mathrm{D}}\right)^{2}[\mathbf{I}]=[\mathbf{D}] \cdot[\mathbf{D}]^{\mathrm{T}}$, it is noticed that $\sigma_{\mathrm{F}}$ represents the variance of output and $\sigma_{\mathrm{D}}$ represents the variance of output respectively. Their ratio $\left(\sigma_{\mathrm{F}} / \sigma_{\mathrm{D}}\right)$ can definitely be considered as the sensitivity as well. Let's call it $\mathrm{S}_{\mathrm{v}}$

$$
\begin{array}{ll}
\mathrm{S}_{\mathrm{v}}=\sigma_{\mathrm{F}} / \sigma_{\mathrm{D}} & (4-9) \\
\mathrm{S}_{\mathrm{v}}{ }^{2}[\mathbf{I}]=[\mathbf{D}] \cdot[\mathbf{D}]^{\mathrm{T}} & (4-10) \\
\text { assign } & \\
{\left[\mathbf{S}_{\mathrm{v}}\right]=\mathrm{S}_{\mathrm{v}}{ }^{2}[\mathbf{I}]=[\mathbf{D}] \cdot[\mathbf{D}]^{\mathrm{T}}} & (4-11)
\end{array}
$$

and assign

Here this matrix $\left[\mathbf{S}_{\mathbf{v}}\right.$ ] is called the sensitive matrix. According to the $\left[\mathbf{S}_{\mathbf{v}}\right]$ expression, it can be derived that:

1. [ $\left.\mathbf{S}_{\mathbf{v}}\right]$ has to be a diagonal matrix, and

2. All its elements on the main diagonal are identical.

If a design is uncoupled, its sensitive matrix will always have the first feature. However, it may or may not satisfy the second requirement. Further adjustments may be needed.

\section{LCA - Environmental Analysis}

One of the design evaluations is environmental analysis, which can be done by using lifecycle assessment (LCA) techniques. However, the practical application of LCA during the design stage is still a major challenge as these techniques are complex and time-consuming. This paper provides a simplified LCA approach with a detailed analysis method and evaluation tables. The approach, together with the PBA (process-based analysis) concept, can be applied to each of the four lifecycle stages and to every single process within each stage.

LCA was developed to cover all four stages of the lifecycle - extraction, production, operation, and retirement. However, gathering reliable data on environmental impact can be challenging, particularly for those aspects, such as raw material, that are outside the control of the product manufacturer. For this reason, individual assessments may focus on those aspects that are under the control of the company performing the analysis. Usually quantitative analysis is not necessary for new product development. Most of the simplified LCA techniques are used for internal purposes without formal requirements for reporting. Prospective users generally are not interested in detailed quantities, but rather in the relative difference among the possible design alternatives.

Based on the lifecycle model, each process in a lifecycle stage has inputs and outputs. As discussed earlier, along the LCA stream, inputs include materials and energy while outputs can be airborne emissions, waterborne effluents and solid wastes. Through the process-based analysis, each process can have its own environmental impact evaluation, in respect to resources (materials and energy) and potential gaseous, liquid and solid pollutants. In turn, each stage can conduct its environmental evaluation by combining the results of its processes. The integration of all stages can determine the general environmental impact of the lifecycle. Thus, it is required to conduct assessments for the product's every material and process. Materials determine the product's physical structure, while processes make up the product's lifecycle. If the assessment result indicates that improvement is needed related to the physical structure or lifecycle design, a design change can be made to the specific material or process. This makes it possible to apply LCA dynamically into design iterations. As mentioned above, the approach will follow simplified LCA, using mainly qualitative analysis techniques.

Table 2 is designed to collect information for each individual process, in order to conduct a process-based analysis. The six most important impact sections are listed in the table - material, energy, air emission, water effluent, solid waste and eco-toxicant. Each section will detail all items that may cause any impact. Every item will obtain a rating value according to specific criteria. Combining all the items' rating values, with regards to their weighting within their section, will give an assessment value for that section. The values from all six sections make up an array for that process, called a process assessment array. The eco-toxicant section is equipped to express any overwhelming items that may be involved in the process. If this occurs, the other section items' ratings become meaningless.

As an example of a rating system, AT\&T has adopted a rating of $0 \sim 4$, in respect to its own assessment approach. They use 0 to depict the highest impact, while 4 denotes the lowest [Todd et al., 1999] and [Graedel et al., 1995].

Most processes can be rated from 0 to 5 . One may prefer setting 0 as least impact and 5 as most impact.

Table 3 is used to gather all the process assessment arrays (PA) of each stage. A stage 
assessment array (SA) will be derived by integrating all PAs together. Table 4 shows a lifecycle assessment matrix (LM). This matrix reflects the whole lifecycle assessment result.

In this qualitative streamlined lifecycle analysis, functional units and allocation methods are not explicitly considered. However, the use of virgin materials is penalized because credit is given for using recycled materials. Users of the matrix are required to allocate numeric values, by material type, for sustainable and environmental attributes for each product being evaluated. The ideal score is zero. This approach reflects the philosophy that less is better and the least is best. Thus, the approach is intended to reward product developers for creating resource- efficient products. The numeric values are subjective and company specific. The values used should be consistent with each company's internal business, social and environmental ethics and goals.

Each cell in the lifecycle matrix may have an integer value $(0-5)$, which is derived from the lifecycle process analysis. Once an evaluation is done using the matrix approach, an overall environmentally responsible product rating can be computed as the sum of the matrix elements:

$$
\mathrm{I}_{\text {Sum }}=\sum \sum L M_{i j}
$$

where $\mathrm{I}_{\text {Sum }}$ is the whole rating. The less it is, the better the design is in term of its environmental impact. There are 24 cells in the matrix. The matrices provide a useful overall assessment of a product design.

Table 2. Process Assessment Table:

\begin{tabular}{|c|c|c|c|c|c|c|c|c|c|c|c|c|}
\hline \multirow{3}{*}{$\begin{array}{c}\text { Process } \\
\text { Name }\end{array}$} & \multicolumn{4}{|c|}{ Inputs } & \multicolumn{8}{|c|}{$\begin{array}{l}\text { Outputs } \\
\end{array}$} \\
\hline & \multicolumn{2}{|c|}{ Material } & \multicolumn{2}{|c|}{ Energy } & \multicolumn{2}{|c|}{ Air Emission } & \multicolumn{2}{|c|}{ Water Effluent } & \multicolumn{2}{|c|}{ Solid Waste } & \multicolumn{2}{|c|}{ Eco Toxicant } \\
\hline & Item & Rating & Item & Rating & Item & Rating & Item & Rating & Item & Rating & Item & Rating \\
\hline & & & & & & & & & & & & $\overline{\mathrm{X}}$ \\
\hline & & & & & & & & & & & & $\mathrm{X}$ \\
\hline & & & & & & & & & & & & $\mathrm{X}$ \\
\hline & & & & & & & & & & & & $\mathrm{X}$ \\
\hline & & & & & & & & & & & & $\mathrm{X}$ \\
\hline$\overline{\mathbf{P A}_{\mathbf{n}}}$ & $100 \%$ & & $100 \%$ & & $100 \%$ & & $100 \%$ & & $100 \%$ & & $100 \%$ & $\bar{X}$ \\
\hline
\end{tabular}

Table 3. Stage Assessment Table:

\begin{tabular}{|c|c|c|c|c|c|c|}
\hline \multirow{3}{*}{ Contributors } & \multicolumn{6}{|c|}{ Impact Rating } \\
\hline & \multicolumn{2}{|c|}{ Inputs } & \multicolumn{4}{|c|}{ 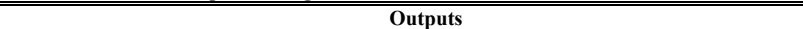 } \\
\hline & Material & Energy & $\begin{array}{l}\text { Air Emission } \\
\end{array}$ & Water Effluent & Solid Waste & $\begin{array}{l}\text { Eco Toxicant } \\
\end{array}$ \\
\hline Process $1\left(\mathrm{PA}_{1}\right)$ & & & & & & $\bar{x}$ \\
\hline Process $2\left(\mathrm{PA}_{2}\right)$ & & & & & & $\mathrm{X}$ \\
\hline Process $3\left(\mathrm{PA}_{3}\right)$ & & & & & & $\mathrm{X}$ \\
\hline & & & & & & $\mathrm{X}$ \\
\hline Process $n\left(\mathrm{PA}_{n}\right)$ & & & & & & $\mathrm{X}$ \\
\hline 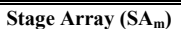 & & & & & & 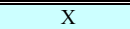 \\
\hline
\end{tabular}

Table 4. Lifecycle Assessment Table: $\left(\mathbf{L M}_{\mathrm{ij}}\right)$

\begin{tabular}{|c|c|c|c|c|c|c|}
\hline \multirow{3}{*}{ Contributors } & \multicolumn{6}{|c|}{ Impact Rating } \\
\hline & \multicolumn{2}{|c|}{ Inputs } & \multicolumn{4}{|c|}{ 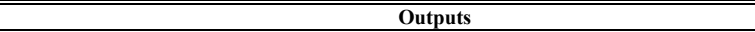 } \\
\hline & Material & \begin{tabular}{c|} 
Energy \\
\end{tabular} & Air Emission & Water Effluent & Solid Waste & EcoToxicant \\
\hline Stage 1 $\left(\mathrm{SA}_{1}\right)$ & $\mathrm{LM}_{11}$ & $\mathrm{LM}_{12}$ & $\mathrm{LM}_{13}$ & & & 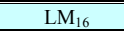 \\
\hline Stage $2\left(\mathrm{SA}_{2}\right)$ & $\mathrm{LM}_{21}$ & $\ldots$ & $\ldots$ & $\ldots$ & $\ldots$ & \\
\hline Stage $3\left(\mathrm{SA}_{3}\right)$ & & & & & & $\mathrm{LM}_{36}$ \\
\hline Stage $4\left(\mathrm{SA}_{4}\right)$ & $\mathrm{LM}_{41}$ & $\ldots$ & $\ldots$ & $\ldots$ & $\mathrm{LM}_{45}$ & $\mathrm{LM}_{46}$ \\
\hline \multicolumn{7}{|l|}{ Subtotal } \\
\hline Sum & & & & & & \\
\hline
\end{tabular}

A product consists of functional modules that are made of components with detailed design parameters. At the beginning of any design, a set of initial values may be needed to start the work. The functional, environmental and economic (FEE) requirements can provide enough information. With present CAD/CAM systems, more detailed information can be obtained. On the other hand, the lifecycle can start from a traditional lifecycle structure. As the lifecycle is selected, processes are determined accordingly and process-based calculations become possible. Based on the impact values, it can be seen which stage, process or material of a product causes the greatest impact. If, in the mean time, the functional and economic evaluations have positive results, the design will lead to a new iteration to obtain a new set of physical and lifecycle structure design parameters. Otherwise, trade-offs among the functional, environmental, and economic optimizations may be necessary.

\section{Case Study}

\section{Lifecycle Quality Analysis}

Piping structure is considered as a statically indeterminate system. It can be separated into elements. Each element's stresses can be calculated in terms of its static loadings and temperature changes. In this case study, a " $Z$ " section was selected. If a support's location was badly selected, a " $Z$ " section's supports are more likely to get a negative reaction 
force, and the pipe's stress to worsen. As shown in Figure 6, the 8" pipe comes from Point A and goes along $\mathrm{X}$ direction. From Point $\mathrm{B}$, it travels in the perpendicular direction, along the $\mathrm{Z}$ axis. At Point $\mathrm{C}$, the pipe changes direction, again perpendicularly, continuing to go along the $\mathrm{X}$ axis to Point $\mathrm{D}$.

Following the current design method, a group of supports will normally be arranged with the experienced span, of every 15 feet in regard to A53 steel. It looks like the one shown in Figure 6. Is this arrangement a good design? Let's start the robust analysis with the mechanical relationship.

Mechanically, it can be simply modelized as a " $Z$ " structure with three supports, as indicated in Figure 6. In another words, the pipe section between supports 3 and 5 is considered. Its static loading includes the uniform weight and two moments at each end due to the internal actions of the separation from the other parts. Based on structural mechanics, this is a statically indetermined structure and can be divided into two pipe elements. Any cross section's stress can be calculated by its internal moment. Obviously, for this structure, the maximum moments will occur at the positions of the supports. Thus, the robustness may be achieved when the stresses are insensitive to those changes of loading. In turn, this requires that the moments be insensitive to the variations of supporting forces, which are determined by the loading. Support B's location will be decided by the following calculation.

Element 3-B-4 consists of 3-B and B-4 pipes. Their lengths and weights are $\mathrm{L}_{3 \mathrm{~B}}, \mathrm{~L}_{4 \mathrm{~B}}, \mathrm{~W}_{3 \mathrm{~B}}$, and $\mathrm{W}_{4 \mathrm{~B}}$. Element 4-C-5 consists of 4-C and C-5 pipes. Their lengths and weights are $\mathrm{L}_{4 \mathrm{C}}, \mathrm{L}_{5 \mathrm{C}}, \mathrm{W}_{4 \mathrm{C}}$, and $\mathrm{W}_{5 \mathrm{C}}$.

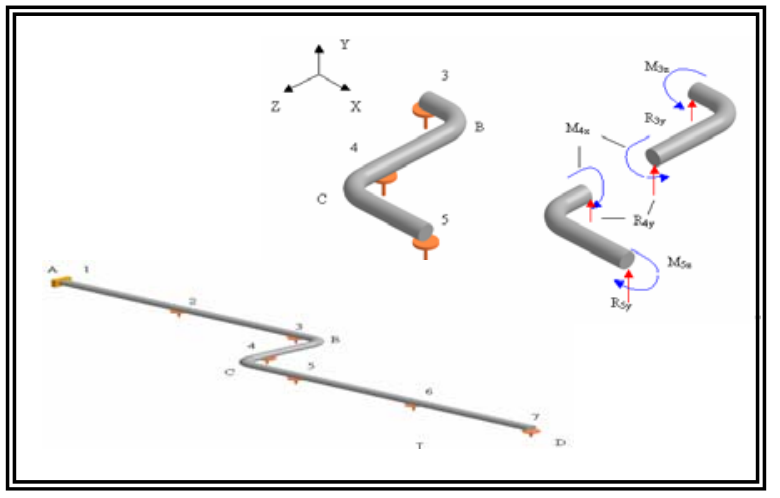

Figure 6. Structural Analysis

Because

$$
\begin{aligned}
& \sum \mathrm{M}_{\mathrm{x}}=0 \\
& \sum \mathrm{M}_{\mathrm{z}}=0 \\
& \sum \mathrm{F}_{\mathrm{z}}=0
\end{aligned}
$$

Thus,

$$
\begin{aligned}
& \mathrm{M}_{3 \mathrm{z}}=\mathrm{R}_{3 \mathrm{y}} \cdot \mathrm{L}_{3 \mathrm{~B}}-\mathrm{W}_{3 \mathrm{~B}} \cdot \mathrm{L}_{3 \mathrm{~B}} / 2 \\
& \mathrm{M}_{4 \mathrm{x}}=\mathrm{R}_{4 \mathrm{y}} \cdot \mathrm{L}_{4 \mathrm{~B}}-\mathrm{W}_{4 \mathrm{~B}} \cdot \mathrm{L}_{4 \mathrm{~B}} / 2,
\end{aligned}
$$

or

$$
\begin{aligned}
& \mathrm{M}_{4 \mathrm{x}}=\mathrm{R}_{4 \mathrm{y}} \cdot \mathrm{L}_{4 \mathrm{C}}-\mathrm{W}_{4 \mathrm{C}} \cdot \mathrm{L}_{4 \mathrm{C}} / 2 \\
& \mathrm{M}_{5 \mathrm{z}}=\mathrm{R}_{5 \mathrm{y}} \cdot \mathrm{L}_{5 \mathrm{C}}-\mathrm{W}_{5 \mathrm{C}} \cdot \mathrm{L}_{5 \mathrm{C}} / 2 \\
& \mathrm{R}_{3 \mathrm{y}}+\mathrm{R}_{4 \mathrm{y}}+\mathrm{R}_{5 \mathrm{y}}=\mathrm{W}_{3 \mathrm{~B}}+\mathrm{W}_{4 \mathrm{~B}}+\mathrm{W}_{4 \mathrm{C}}+\mathrm{W}_{5 \mathrm{C}}
\end{aligned}
$$

The above functions represent the mechanical relationships among the structural strength, the supports, and the loads. If the performance function $\mathbf{F r}=[\mathbf{D}] \cdot \mathbf{D p}$ is constructed as:

$$
\mathbf{M}=[\mathbf{D}] \cdot \mathbf{R}
$$

where $\mathbf{M}=\left[\mathrm{M}_{3 \mathrm{z}}, \mathrm{M}_{4 \mathrm{x}}, \mathrm{M}_{5 \mathrm{z}}\right]$ and $\mathbf{R}=\left[\mathrm{R}_{3 \mathrm{y}}, \mathrm{R}_{4 \mathrm{y}}, \mathrm{R}_{5 \mathrm{y}}\right]$ Then

$$
\begin{aligned}
& \text { [ D ] = } \\
& {\left[\begin{array}{lll}
\partial \mathrm{M}_{3 \mathrm{z}} / \partial \mathrm{R}_{3 \mathrm{y}} & \partial \mathrm{M}_{3 \mathrm{z}} / \partial \mathrm{R}_{4 \mathrm{y}} & \partial \mathrm{M}_{3 \mathrm{z}} / \partial \mathrm{R}_{5} \\
\partial \mathrm{M}_{4 \mathrm{x}} / \partial \mathrm{R}_{3 \mathrm{y}} & \partial \mathrm{M}_{4 \mathrm{x}} / \partial \mathrm{R}_{4 \mathrm{y}} & \partial \mathrm{M}_{4 \mathrm{x}} / \partial \mathrm{R}_{5 \mathrm{y}} \\
\partial \mathrm{M}_{5 \mathrm{z}} / \partial \mathrm{R}_{3 \mathrm{y}} & \partial \mathrm{M}_{5 \mathrm{z}} / \partial \mathrm{R}_{4 \mathrm{y}} & \partial \mathrm{M}_{5 \mathrm{z}} / \partial \mathrm{R}_{5 \mathrm{y}}
\end{array}\right]}
\end{aligned}
$$
According to the above equations, the following relationships can be derived:

$$
\begin{aligned}
& \partial \mathrm{M}_{3 \mathrm{z}} / \partial \mathrm{R}_{3 \mathrm{y}}=\mathrm{L}_{3 \mathrm{~B}}, \partial \mathrm{M}_{3 \mathrm{z}} / \partial \mathrm{R}_{4 \mathrm{y}}=0, \quad \partial \mathrm{M}_{3 \mathrm{z}} / \partial \mathrm{R}_{5 \mathrm{y}}=0 \\
& \partial \mathrm{M}_{4 \mathrm{x}} / \partial \mathrm{R}_{3 \mathrm{y}}=0, \quad \partial \mathrm{M}_{4 \mathrm{x}} / \partial \mathrm{R}_{4 \mathrm{y}}=\mathrm{L}_{4 \mathrm{~B}}, \partial \mathrm{M}_{4 \mathrm{x}} / \partial \mathrm{R}_{5 \mathrm{y}}=0 \\
& \partial \mathrm{M}_{5 \mathrm{z}} / \partial \mathrm{R}_{3 \mathrm{y}}=0, \partial \mathrm{M}_{5 \mathrm{z}} / \partial \mathrm{R}_{4 \mathrm{y}}=0, \quad \partial \mathrm{M}_{5 \mathrm{z}} / \partial \mathrm{R}_{5 \mathrm{y}}=\mathrm{L}_{5 \mathrm{C}}
\end{aligned}
$$

Thus,

$$
[\mathbf{D}]=\left[\begin{array}{ccl}
\mathrm{L}_{3 \mathrm{~B}} & 0 & 0 \\
0 & \mathrm{~L}_{4 \mathrm{~B}} & 0 \\
0 & 0 & \mathrm{~L}_{5 \mathrm{C}}
\end{array}\right]
$$

Thus, the sensitive matrix is:

$$
\left[\mathbf{S}_{\mathbf{v}}\right]=[\mathbf{D}] \cdot[\mathbf{D}]^{\mathrm{T}}=\left[\begin{array}{ccl}
\mathrm{L}_{3 \mathrm{~B}}{ }^{2} & 0 & 0 \\
0 & \mathrm{~L}_{4 \mathrm{~B}}{ }^{2} & 0 \\
0 & 0 & \mathrm{~L}_{5 \mathrm{C}}{ }^{2}
\end{array}\right]
$$

According to the robust features of the sensitive matrix, we have:

$$
\mathrm{L}_{3 \mathrm{~B}}{ }^{2}=\mathrm{L}_{4 \mathrm{~B}}{ }^{2}=\mathrm{L}_{5 \mathrm{C}}{ }^{2}
$$

If using $\mathrm{M}_{4 \mathrm{x}}=\mathrm{R}_{4 \mathrm{y}} \cdot \mathrm{L}_{4 \mathrm{C}}-\mathrm{W}_{4 \mathrm{C}} \cdot \mathrm{L}_{4 \mathrm{C}} / 2$, instead of using $\mathrm{M}_{4 \mathrm{x}}=\mathrm{R}_{4 \mathrm{y}} \cdot \mathrm{L}_{4 \mathrm{~B}}-\mathrm{W}_{4 \mathrm{~B}} \cdot \mathrm{L}_{4 \mathrm{~B}} / 2$, in the above manipulation, then it also can be derived:

$$
\mathrm{L}_{3 \mathrm{~B}}{ }^{2}=\mathrm{L}_{4 \mathrm{c}}{ }^{2}=\mathrm{L}_{5 \mathrm{C}}{ }^{2}
$$

The physical structure must satisfy $\mathrm{L}_{3 \mathrm{~B}}=\mathrm{L}_{4 \mathrm{~B}}=\mathrm{L}_{4 \mathrm{C}}=$ $\mathrm{L}_{5 \mathrm{C}}$ to achieve robustness. This means the " $\mathrm{Z}$ " section should have the structural form as shown in Figure 5.

It can also be explained from the perspective of geometry. As indicated in Figure 6, the robust design result indicates that the "Z" structure should have a support at its gravity center - the only best position. Other structures whose gravity centers are apart from their structural components will have to have their supports located on the same side with their general gravity centers. The further away, the better. However, this can be limited by the sizes of the physical structures. The best position may never be achieved. 


\section{Lifecycle Assessment}

The same " $Z$ " section of a piping structure system is also evaluated through the lifecycle assessment (LCA) stream. The section has steel pipes with concrete supports. When it arrives at the retirement stage, most steel pipes can be recycled, while the concrete supports will be sent to the landfill. The initial physical structure and lifecycle structure are given as follows:

Its physical structure has;

- Pipes and fittings - Steel

- Support-Concrete

With regards to the lifecycle structure in this case, boundary conditions were set up from the production stage, through the operation stage, to the retirement stage. The extraction stage was excluded for unachievable data reasons. Thus, there were three main stages involved in the lifecycle evaluation Stages 2, 3, and 4 (no Stage 1).

The lifecycle structure has;

- Production stage - the manufacturing processes

- Operation stage - a single process of use

- Retirement stage - the recycle and landfill processes

Within the assessment tables, each item was rated, based on a scale of 0 to 5 . The rating value was simply decided by its impact level for the purpose of this research. In practice, the criteria may be set up according to individual experience.

\section{Production Stage:}

Table 5. Process Assessment Table: (Manufacturing)

\begin{tabular}{|c|c|c|c|c|c|c|c|c|c|c|c|c|}
\hline \multirow[t]{2}{*}{ Pr } & \multicolumn{4}{|c|}{ Inputs } & \multicolumn{8}{|c|}{ 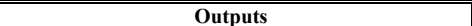 } \\
\hline & \multicolumn{2}{|c|}{ Mat. } & \multicolumn{2}{|c|}{ Ene. } & \multicolumn{2}{|c|}{ A.Em. } & \multicolumn{2}{|c|}{ W.Ef. } & \multicolumn{2}{|c|}{ S.Wa. } & \multicolumn{2}{|c|}{ 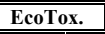 } \\
\hline \multirow[t]{3}{*}{ Mf } & It. & $\mathbf{R}$ & It. & $\mathbf{R}$ & It. & $\mathbf{R}$ & It & $\mathbf{R}$ & It. & $\mathrm{R}$ & It. & $\mathbf{R}$ \\
\hline & $\overline{\mathrm{SStl}}$ & 3 & Ele & 2 & & & & & stl & $\bar{~} 1$ & & $\mathrm{x}$ \\
\hline & $\mathrm{Cr}$ & 2 & Mlt & 1 & Mlt & 2 & Mlt & 1 & Mlt & 1 & & $\mathrm{x}$ \\
\hline $\begin{array}{l}\mathbf{P a} \\
\end{array}$ & \%\% & 3 & $\overline{~ \% ~}$ & 2 & $\%$ & 2 & \% & 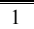 & $\%$ & 1 & \%\% & X \\
\hline
\end{tabular}

Table 6. Stage Assessment Table: (Production)

\begin{tabular}{||c||c|c||c|c|c||c|}
\hline \multirow{3}{*}{ Ctr. } & \multicolumn{5}{|c|}{ Impact Rating } \\
\cline { 2 - 7 } & \multicolumn{2}{|c|}{ Inputs } & \multicolumn{3}{c|}{ Outputs } \\
\cline { 2 - 7 } & Mat. & Ene. & A.Em. & W.Ef. & S.Wa. & EcoTox. \\
\hline \hline $\mathrm{PA}_{1}$ & 3 & 2 & 2 & 1 & 1 & $\mathrm{X}$ \\
\hline \hline $\mathrm{SA}_{2}$ & 3 & 2 & 2 & 1 & 1 & $\mathrm{X}$ \\
\hline \hline
\end{tabular}

\section{Operation Stage:}

Table 7. Process Assessment Table: (Use)

\begin{tabular}{|c|c|c|c|c|c|c|c|c|c|c|c|c|}
\hline \multirow[t]{2}{*}{ Pr } & \multicolumn{4}{|c|}{ Inputs } & \multicolumn{8}{|c|}{ 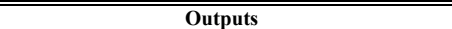 } \\
\hline & & & EI & & $\overline{\text { A.1. }}$ & & & & S.W & & Eco? & \\
\hline $\begin{array}{l}\text { Use } \\
\end{array}$ & $\begin{array}{l}\text { It } \\
\end{array}$ & 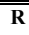 & "It. & $\overline{\bar{R}}$ & $\overline{~ I t . ~}$ & T & 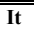 & 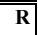 & $\begin{array}{l}\text { It. } \\
\end{array}$ & \begin{tabular}{l|l|}
$\mathbf{R}$ \\
\end{tabular} & IIt. & 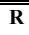 \\
\hline 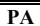 & \% & 0 & $\%$ & 0 & \% & 0 & \% & 0 & $\overline{\%}$ & 0 & $\overline{\%}$ & $X$ \\
\hline
\end{tabular}

Table 8. Stage Assessment Table: (Operation)

\begin{tabular}{|c|c|c|c|c|c|c|}
\hline \multirow{3}{*}{ Ctr. } & \multicolumn{6}{|c|}{ Impact Rating } \\
\hline & \multicolumn{2}{|c|}{ Inputs } & \multicolumn{4}{|c|}{ Outputs } \\
\hline & Mat. & Ene. & A.Em. & W.Ef. & S.Wa. & EcoTox. \\
\hline$\overline{\mathrm{PA}_{1}}$ & $\overline{00}$ & $\overline{0}$ & $\overline{00}$ & $\overline{00}$ & $\overline{0}$ & $\overline{\mathrm{X}}$ \\
\hline$\overline{\mathbf{S A}_{3}}$ & $\overline{00}$ & $\overline{00}$ & $\bar{~} \overline{0}$ & $\bar{~} \overline{0}$ & $\bar{~} \overline{0}$ & $\overline{\bar{X}}$ \\
\hline
\end{tabular}

Retirement Stage:

Table 9. Process Assessment Table: (Recycle)

\begin{tabular}{|c|c|c|c|c|c|c|c|c|c|c|c|c|}
\hline \multirow[t]{2}{*}{ Pr } & \multicolumn{4}{|c|}{ Inputs } & \multicolumn{8}{|c|}{ Outputs } \\
\hline & \multicolumn{2}{|c|}{ Mat. } & \multicolumn{2}{|c|}{ Ene. } & \multicolumn{2}{|c|}{$\begin{array}{l}\text { A.E } \\
\text { m. }\end{array}$} & \multicolumn{2}{|c|}{ W.Ef. } & \multicolumn{2}{|c|}{ S.Wa. } & \multicolumn{2}{|c|}{ EcoTox. } \\
\hline Lanf. & It. & $\mathbf{R}$ & It. & $\mathbf{R}$ & It. & $\mathbf{R}$ & It & $\mathbf{R}$ & It. & $\mathbf{R}$ & It. & $\mathbf{R}$ \\
\hline & & & Mlt & 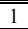 & & & & & steel &  & & $\overline{\mathrm{X}}$ \\
\hline $\mathbf{P A _ { 1 }}$ & $\%$ & 0 & $\%$ & 1 & $\%$ & 0 & $\%$ & 0 & $\%$ & 0 & $\%$ & $\mathrm{X}$ \\
\hline
\end{tabular}

Table 9. Process Assessment Table: (Landfill)

\begin{tabular}{|c|c|c|c|c|c|c|c|c|c|c|c|c|}
\hline \multirow[t]{2}{*}{ Pr } & \multicolumn{4}{|c|}{ Inputs } & \multicolumn{8}{|c|}{ Outputs } \\
\hline & \multicolumn{2}{|c|}{ Mat. } & \multicolumn{2}{|c|}{ Ene. } & \multicolumn{2}{|c|}{$\begin{array}{l}\text { A.E } \\
\text { m. }\end{array}$} & \multicolumn{2}{|c|}{ W.Ef. } & \multicolumn{2}{|c|}{ S.Wa. } & \multicolumn{2}{|c|}{ EcoTox. } \\
\hline Lanf. & It. & $\overline{\mathrm{R}}$ & It. & $\overline{\mathrm{R}}$ & It. & $\mathbf{R}$ & It & IR & It. & 奋 & It. & $\overline{\mathrm{R}}$ \\
\hline & & & & & & & & & $\mathrm{Cr}$ & 3 & & $\mathrm{X}$ \\
\hline $\mathbf{P A}_{2}$ & $\%$ & 0 & $\%$ & 0 & $\%$ & 0 & $\%$ & 0 & $\%$ & 3 & $\%$ & $\mathrm{X}$ \\
\hline
\end{tabular}

Table 10. Stage Assessment Table: (Retirement)

\begin{tabular}{|c|c|c|c|c|c|c|}
\hline \multirow{3}{*}{ Ctr. } & \multicolumn{6}{|c|}{ Impact Rating } \\
\hline & \multicolumn{2}{|c|}{ Inputs } & \multicolumn{4}{|c|}{ Outputs } \\
\hline & Mat. & Ene. & A.Em. & W.Ef. & S.Wa. & EcoTox. \\
\hline $\mathrm{PA}_{1}$ & 0 & 1 & 0 & 0 & 0 & $\mathrm{X}$ \\
\hline $\mathrm{PA}_{2}$ & 0 & 0 & 0 & 0 & 3 & $\mathrm{X}$ \\
\hline $\mathbf{S A}_{4}$ & 0 & 1 & 0 & 0 & 3 & $\bar{X}$ \\
\hline
\end{tabular}

Table 11. Lifecycle Assessment Table: (LM)

\begin{tabular}{|c|c|c|c|c|c|c|}
\hline \multirow{3}{*}{ Ctr. } & \multicolumn{6}{|c|}{ Impact Rating } \\
\hline & \multicolumn{2}{|c|}{ Inputs } & \multicolumn{4}{|c|}{ Outputs } \\
\hline & Mat. & Ene. & A.Em. & W.Ef. & S.Wa. & EcoTox. \\
\hline $\mathrm{SA}_{1}$ & $\mathrm{X}$ & $\mathrm{X}$ & $\mathrm{X}$ & $\bar{X}$ & $\mathrm{X}$ & $\mathrm{X}$ \\
\hline $\mathrm{SA}_{2}$ & 3 & 2 & 2 & 1 & 1 & 0 \\
\hline $\mathrm{SA}_{3}$ & 0 & 0 & 0 & 0 & 0 & 0 \\
\hline $\mathrm{SA}_{4}$ & 0 & 1 & 0 & 0 & 3 & 0 \\
\hline \begin{tabular}{c|} 
Sub \\
\end{tabular} & 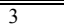 & 3 & 2 & $\bar{~} 1$ & 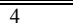 & $\overline{00}$ \\
\hline Sum & \multicolumn{6}{|c|}{13} \\
\hline
\end{tabular}

The total impact value is 13 , which is mostly due to the material consumption and solid wastes. The concrete supports have the most potential for improvement. This suggests that the lifecycle structure adopt a recycling process to increase the lifespan of the material and eliminate the discards. Accordingly, the physical structure may change to use recyclable steel for the supports, thereby minimizing the impact on natural resources. Thus, new physical structure has:

- Pipes and fittings - Steel A

- Supports - Steel B

The life cycle structure will change to,

- Production stage - the manufacturing process

- Operation stage - the process of use

- Retirement stage - the recycle process

The production and retirement assessment arrays need to be updated. Because all major parts are capable of using recycled materials, thereby reducing the use of new materials and the need for manufacturing, accordingly it has,

\section{Production Stage:}

Table 5. Process Assessment Table: (Manufacturing)

\begin{tabular}{|c|c|c|c|c|c|c|c|c|c|c|c|c|}
\hline \multirow[t]{2}{*}{ Pr } & \multicolumn{4}{|c|}{ Inputs } & \multicolumn{8}{|c|}{ Outputs } \\
\hline & \multicolumn{2}{|c|}{ Mat. } & \multicolumn{2}{|c|}{ Ene. } & \multicolumn{2}{|c|}{ A.Em. } & \multicolumn{2}{|c|}{ W.Ef. } & \multicolumn{2}{|c|}{ S.Wa. } & \multicolumn{2}{|c|}{ EcoTox. } \\
\hline \multirow[t]{3}{*}{$\begin{array}{l}\mathbf{M f} \\
\end{array}$} & 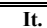 & $\overline{\mathbf{R}}$ & IIt. & $\begin{array}{l}\mathbf{R} \\
\end{array}$ &  & 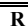 & 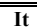 & 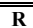 & IIt. & 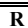 & $\overline{\overline{\text { It. }}}$ & $\overline{\overline{\mathbf{R}}}$ \\
\hline & (Stla & 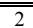 & Ele & $\begin{array}{ll}1 \\
\end{array}$ & & & & & SStla & 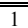 & & $\overline{\bar{X}}$ \\
\hline & Stlb & 1 & & & & & & & Stlb & 1 & & $\mathrm{X}$ \\
\hline$\overline{\overline{P a}}$ & 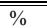 & 2 & $\overline{~ \% \%}$ & $\bar{~} 1$ & 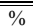 &  & $\overline{~ \% \%}$ & 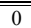 & 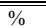 & 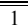 & $\overline{~ \% \%}$ & $\overline{\overline{X X}}$ \\
\hline
\end{tabular}


Table 6. Stage Assessment Table: (Production)

\begin{tabular}{||l||l|l|l|l|l||c||}
\hline \multirow{3}{*}{ Ctr. } & \multicolumn{6}{|c||}{ Impact Rating } \\
\cline { 2 - 7 } & \multicolumn{2}{|c|}{ Inputs } & \multicolumn{3}{c||}{ Outputs } \\
\cline { 2 - 7 } & Mat. & Ene. & A.Em. & W.Ef. & S.Wa. & EcoTox. \\
\hline \hline $\mathrm{PA}_{1}$ & 2 & 1 & 0 & 0 & 1 & $\mathrm{X}$ \\
\hline \hline $\mathbf{S A}_{2}$ & 2 & 1 & 0 & 0 & 1 & $\mathrm{X}$ \\
\hline \hline
\end{tabular}

Operation Stage:

Table 7. Process Assessment Table: (Use)

\begin{tabular}{|c|c|c|c|c|c|c|c|c|c|c|c|c|}
\hline \multirow[t]{2}{*}{ Pr } & \multicolumn{4}{|c|}{ Inputs } & \multicolumn{8}{|c|}{ Outputs } \\
\hline & \multicolumn{2}{|c|}{ Mat. } & \multicolumn{2}{|c|}{ Ene. } & \multicolumn{2}{|c|}{$\begin{array}{l}\text { A.Em. } \\
\text { A. }\end{array}$} & \multicolumn{2}{|c|}{ W.Ef. } & \multicolumn{2}{|c|}{ S.Wa. } & \multicolumn{2}{|c|}{ EcoTox. } \\
\hline $\begin{array}{l}\text { Use } \\
\end{array}$ & It. & $\mathbf{R}$ & It. & $\overline{\bar{R}}$ & It. & $\overline{\underline{R}}$ & IIt & $\begin{array}{ll}\mathbf{R} \\
\end{array}$ & IIt. & $\mathbf{R}$ & It. & $\begin{array}{ll}\mathbf{R} \\
\end{array}$ \\
\hline & & & & & & & & & & & & $\mathrm{X}$ \\
\hline$\overline{\mathbf{P A}_{1}}$ & \%\% & 0 & \%\% & 0 & 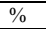 & $\overline{0}$ & $\%$ & 0 & $\%$ & 0 & \% & $\mathrm{x}$ \\
\hline
\end{tabular}

Table 8. Stage Assessment Table: (Operation)

\begin{tabular}{|c|c|c|c|c|c|c|}
\hline \multirow{3}{*}{ Ctr. } & \multicolumn{6}{|c|}{ Impact Rating } \\
\hline & \multicolumn{2}{|c|}{ Inputs } & \multicolumn{4}{|c|}{ Outputs } \\
\hline & Mat. & Ene. & A.Em. & W.Ef. & S.Wa. & EcoTox. \\
\hline$\overline{\mathrm{PA}_{1}}$ & $\bar{~} \overline{0}$ & $\bar{~} \overline{0}$ & 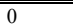 &  & $\bar{~} 0$ & $\overline{\bar{X}}$ \\
\hline $\mathbf{S A}_{3}$ & 0 & 0 & 0 & 0 & 0 & $\mathrm{X}$ \\
\hline
\end{tabular}

\section{Retirement Stage:}

Table 9. Process Assessment Table: (Recycle)

\begin{tabular}{|c|c|c|c|c|c|c|c|c|c|c|c|c|}
\hline \multirow[t]{2}{*}{ Pr } & \multicolumn{4}{|c|}{ Inputs } & \multicolumn{8}{|c|}{ Outputs } \\
\hline & \multicolumn{2}{|c|}{ Mat. } & \multicolumn{2}{|c|}{$\overline{E \text { Ene. }}$} & \multicolumn{2}{|c|}{$\begin{array}{l}\text { A.Em. } \\
\end{array}$} & \multicolumn{2}{|c|}{ W.Ef. } & \multicolumn{2}{|c|}{ S.Wa. } & \multicolumn{2}{|c|}{$\begin{array}{l}\text { EcoTox. } \\
\end{array}$} \\
\hline Lanf. & IIt. & \begin{tabular}{|l|l|}
$\mathbf{R}$ \\
\end{tabular} & It. & $\overline{\bar{R}}$ & It. & $\overline{\overline{\mathbf{R}}}$ & 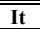 & $\begin{array}{ll}\mathbf{R} \\
\end{array}$ & It. & $\begin{array}{ll}\mathbf{R} \\
\end{array}$ & It. & $\overline{|l|}$ \\
\hline & & & Mlt & 11 & & & & & steel & 1 & & $\mathrm{X}$ \\
\hline $\mathbf{P A}_{1}$ & $\%$ & 0 & $\%$ & 1 & $\%$ & 0 & $\%$ & 0 & $\%$ & 1 & $\%$ & $x$ \\
\hline
\end{tabular}

Table 10. Stage Assessment Table: (Retirement)

\begin{tabular}{|c||c|c||l|l|l||c||}
\hline \multirow{3}{*}{ Ctr. } & \multicolumn{3}{|c||}{ Impact Rating } \\
\cline { 2 - 7 } & \multicolumn{2}{|c|}{ Inputs } & \multicolumn{3}{c||}{ Outputs } \\
\cline { 2 - 7 } & Mat. & Ene. & A.Em. & W.Ef. & S.Wa. & EcoTox. \\
\hline \hline $\mathrm{PA}_{1}$ & 0 & 1 & 0 & 0 & 1 & $\mathrm{X}$ \\
\hline \hline $\mathrm{SA}_{\mathbf{4}}$ & 0 & 1 & 0 & 0 & 1 & $\mathrm{X}$ \\
\hline \hline
\end{tabular}

Table 11. Lifecycle Assessment Table: (LM)

\begin{tabular}{||c||c|c||c|c|c|c||}
\hline \multirow{3}{*}{ Ctr. } & \multicolumn{9}{c||}{ Impact Rating } \\
\cline { 2 - 8 } & \multicolumn{2}{|c|}{ Inputs } & \multicolumn{4}{c||}{ Outputs } \\
\cline { 2 - 8 } & Mat. & Ene. & A.Em. & W.Ef. & S.Wa. & EcoTox. \\
\hline \hline $\mathrm{SA}_{1}$ & $\mathrm{X}$ & $\mathrm{X}$ & $\mathrm{X}$ & $\mathrm{X}$ & $\mathrm{X}$ & $\mathrm{X}$ \\
\hline $\mathrm{SA}_{2}$ & 2 & 1 & 0 & 0 & 1 & 0 \\
\hline $\mathrm{SA}_{3}$ & 0 & 0 & 0 & 0 & 0 & 0 \\
\hline $\mathrm{SA}_{4}$ & 0 & 1 & 0 & 0 & 1 & 0 \\
\hline \hline Sub & 2 & 2 & 0 & 0 & 2 & 0 \\
\hline \hline Sum & \multicolumn{7}{|c|}{6} \\
\hline
\end{tabular}

Obviously, the new lifecycle structure with the conditioning and reuse processes significantly reduces the total impact.

$$
\mathrm{I}_{\text {Sum }}=13\left(\text { the } 1^{\text {st }}\right. \text { design) }
$$

$\mathrm{I}_{\text {Sum }}=6$ (the $2^{\text {nd }}$ design)

The second design with changes to in its physical structure (steel supports) and lifecycle structure (recycling process) has significantly decreased the environmental impact of the original design. It is more beneficial to the environment. The addition of a recycling process to its retirement stage would also reduce the impact on the environment, thereby improving the design even further.

However, any practical product design requires the simultaneously consideration of the design problems based on environmental, economical and product functionality evaluations. The addition of a new process to any stage could potentially bring an extra lifecycle cost. This means that when a real design concurrently conducts these three evaluations, conflicts may occur among functional, environmental and economical evaluation criteria. This will be the future work of this lifecycle design engineering research project.

\section{Conclusions}

This paper proposed a new lifecycle design process model to address three aspects of sustainable design of function, environment and economy. A new robust design approach and a simplified LCA method have been developed for functional analysis and environmental assessment. The new robust design framework is a general method needs future tests and validation. The simplified LCA approach did not include evaluations of the extraction stage due to limited information. In real-world practice, individual users are able to choose which stages they prefer to include in the approach, based on their own needs. However, the assessment of all four stages is needed to truly reflect the environmental impact of the whole lifecycle.

\section{Acknowledgement}

The authors wish to thank NSERC and an Industrial Consortium for providing financial support through NSERC Design Chair program.

\section{References}

- $\quad$ Angeles, J., 2002, The robust Design of Mechanical Elements and Systems, CSME Forum-02

- Dunsmore, W., Pitts, G., Lewis, S., Sexton, C., Please, C., and Carden, P., 1997, Developing Methodologies for Robust Mechanical Engineering Design, Proceedings of the IME, Vol. 211, Issue 3, P179

- Graedel, T., Allenby, B., and Comrie, P., 1995, Matrix Approaches to abridged Life Cycle Assessment, ES\&T., 29(3) 134A-139A.

- $\quad$ Kim, Y., 2000, Reviewing TRIZ from the Perspective of Axiomatic Design, J. of Eng. Design, V11-1, p79-94.

- $\quad$ Suh, N., 2001, Axiomatic Design - Advances and Applications, Oxford University Press.

- $\quad$ Taguchi, G., Chowdhury, S., and Taguchi, S., 2000, Robust Engineering, McGraw-Hill.

- $\quad$ Todd, J. A. and Curran, M. A., 1999, Streamlined LifeCycle Assessment: Final Report, SETAC North America.

- Zhang, H., Kuo, T., Lu, H., and Huang, S., 1997, Env. Conscious Design and Manuf.: A state-of-the-art survey, J. of Manuf. Sys., 6(5), p352 371.

- $\quad$ Zhang, Y., Wang, H., Zhang, C., 1999, Green QFD-II: a life cycle approach for environmentally conscious manufacturing by integrating $L C A$ and LCC into QFD matrices, Inter. J. of Prod. Res., 37 (5), p1075-1091. 